\title{
En route towards panchromatic light harvesting: photophysical and electrochemical properties of Bodipy-porphyrazine conjugates $\uparrow$
}

\begin{abstract}
S. Kuhri, ${ }^{a}$ V. Engelhardt, ${ }^{\text {b }}$ R. Faust ${ }^{\star b}$ and D. M. Guldi ${ }^{\star a}$
The concept of panchromatic light harvesting, that is, broad absorption cross sections throughout most of the visible range and excited state funnelling, has been realized in a novel set of porphyrazines. On one hand, zinc, copper, or magnesium ions were complexed by porphyrazines to tune their ground and excited state features. On the other hand, up to eight Bodipys were covalently attached to the periphery of the porphyrazines to enhance the ground state absorption. The corresponding star-shaped conjugates were probed by advanced photophysical measurements, that is, time-resolved fluorescence and femtosecond transient absorption spectroscopy. From the latter we derive spectroscopic and kinetic evidence in support of a fast and unidirectional energy transfer from the photoexcited Bodipy at the periphery to the porphyrazine at the core. In addition, the impact of the different metal centers is demonstrated.
\end{abstract}

Received 29th January 2014

DOI: $10.1039 / \mathrm{c} 4 \mathrm{sc00326h}$

www.rsc.org/chemicalscience

conversion. ${ }^{9}$ Notably, phthalocyanines, or more generally, porphyrazines, are usually built up with a low degree of synthetic flexibility as substituents have to be implemented at the precursor stages. ${ }^{\mathbf{9}, \mathbf{1 0}}$ Peripheral annulations of the porphyrazine core have a marked impact on the overall aromaticity of the macrocycle. ${ }^{11}$ As a matter of fact, the electronic and optical properties change. ${ }^{\mathbf{1 2 , 1 3}}$ However, in porphyrazines only a rather moderate absorption cross section evolves between the highenergy B-band and the low-energy Q-band in the 430 to $700 \mathrm{~nm}$ region. ${ }^{14}$

Apart from tetraaza pyrrolic macrocycles, boron dipyrrins (Bodipys) are also of particular interest, especially in the context of light harvesting and energy transfer. Bodipys are well known for their high extinction coefficients, high fluorescence quantum yields, long lived excited states, suitable excited state energies, excellent photostability, and stability in many solvents. ${ }^{15}$

Additionally, the modification of Bodipy is a versatile approach to tailor the absorption/emission properties throughout the 450-680 nm range and to optimize the energy/ electron donor features. ${ }^{\mathbf{1 6 - 1 8}}$ In a few studies, energy transfer between Bodipy and coordinatively linked porphyrins, perylenediimides or subphthalocyanines has been demonstrated. ${ }^{16,19,21}$ Additionally there are some reports with Bodipy porphyrin/phthalocyanine conjugates covalently linked., ${ }^{\mathbf{1 , 2 0 2 2 - 2 4}}$

We recently reported on the synthesis and photophysical investigation of a zinc-containing dibenzoquinoxalino porphyrazine with eight covalently attached Bodipy units (1-/2Zn). ${ }^{24}$ This multi-chromophore light harvesting system reveals efficient intramolecular energy transfer from the photoexcited Bodipy to the porphyrazine and, in addition, shows an efficient 
intermolecular electron transfer from a pyridyl-functionalized phenothiazine coordinated to the photoexcited porphyrazine. ${ }^{23}$ In this paper we focus on the impact of the divalent metal ions in the porphyrazine center on the photophysical properties of the light harvesting system. We describe the preparation of the Bodipy-porphyrazine conjugates 1 and 2 with complexed $\mathrm{Mg}$, $\mathrm{Zn}$ or $\mathrm{Cu}$ ions in the porphyrazine cavity (Chart 1) and discuss their photophysical and electrochemical features as determined by time-resolved fluorescence and femtosecond transient absorption spectroscopy as well as by cyclovoltammety and spectroelectrochemical methods.

\section{Results and discussion}

\section{Synthesis}

The preparation of Bodipy-porphyrazine conjugates 1 and 2 follows routes closely related to those previously published shown in Scheme $1 .^{24}$ Central to the synthesis is compound 3, a versatile building block for highly functionalized porphyrazines. Demetallation of 3-Mg using $p$-toluene sulfonic acid ${ }^{24}$ and the subsequent addition of the corresponding metal acetate lead to 3-Zn (ref. 24) and 3-Cu, respectively. The Bodipy-functionalized alkynes 5 (ref. 25) and 7 (ref. 24) (Chart 2) were connected to porphyrazines $3(\mathrm{Mg}, \mathrm{Zn}$, and $\mathrm{Cu})$ using modified Hagihara-Sonogashira conditions in respectable yields of up to $\mathbf{7 2} \%$ for $\mathbf{1}-\mathbf{C u} / \mathbf{2}-\mathbf{C u}$. The preparation of $\mathbf{1}-\mathbf{Z n} / \mathbf{2}-\mathbf{Z n}^{24}$ and $\mathbf{1}-\mathbf{M g} / \mathbf{2}-$ $\mathrm{Mg}$ posed a significant challenge, as the co-catalyst CuI, commonly used in Hagihara-Sonogashira coupling reactions, was strictly avoided to prevent partial metal ion exchange. Hence the yield of the $\mathrm{Zn} / \mathrm{Mg}$-congeners of $\mathbf{1}$ and $\mathbf{2}$ is somewhat lower than that of the corresponding Cu-porphyrazines.

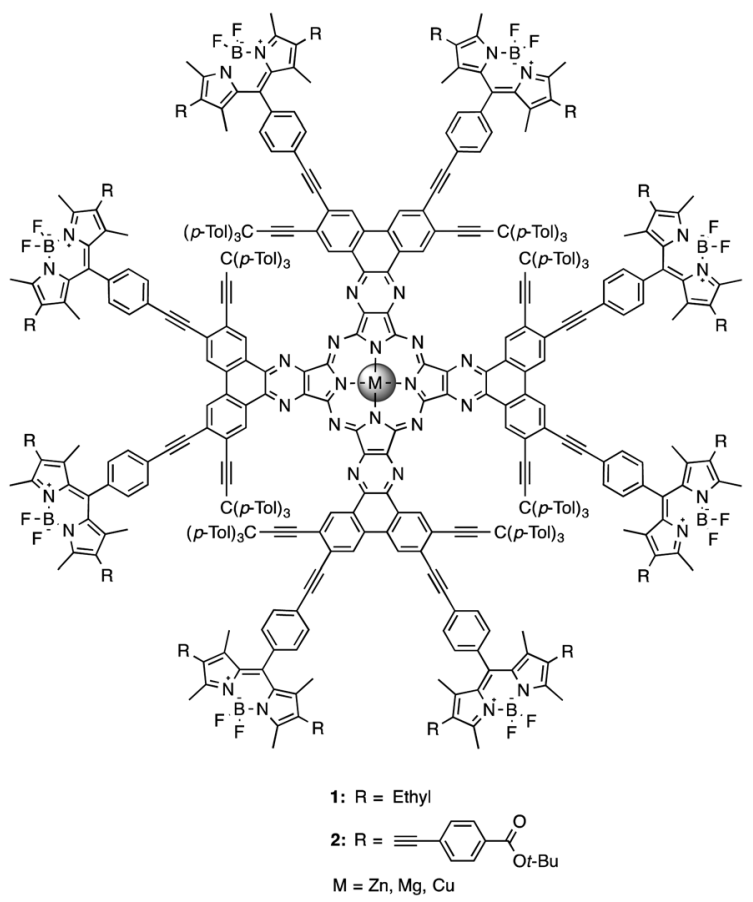

Chart 1 Bodipy-porphyrazine conjugates 1-Zn, 2-Zn, 1-Mg, 2-Mg, 1$\mathrm{Cu}$, and $2-\mathrm{Cu}$

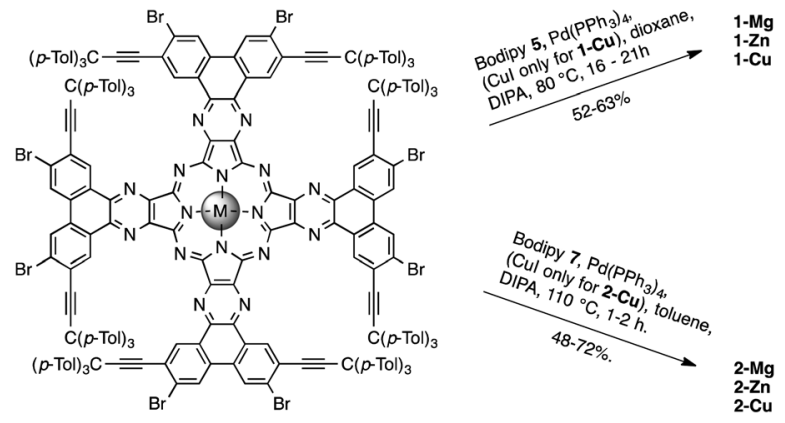

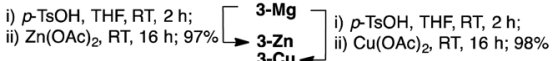

Scheme 1

Reference compound $\mathbf{4}$ (Chart 2) either as a free base $\mathbf{4}-\mathbf{H}_{\mathbf{2}}$ or with complexed $\mathrm{Cu}, \mathrm{Mg}$, or $\mathrm{Zn}$ metal ions could be synthesized along a similar route - see the ESI. $\dagger$

The formation of the sixteen fold alkynylated porphyrazines 1-4 was verified via MALDI mass spectrometry and NMR-spectroscopy - see the ESI. $\hat{\dagger}^{24}$ Difficulties were observed with 2-Mg, for which we were unable to obtain a clear molecular ion signal in the MALDI mass spectrum. However, the constitution of 2-Mg was ascertained by NMR-spectroscopy, which featured characteristic porphyrazine and Bodipy signals in the respective ${ }^{1} \mathrm{H}$ and ${ }^{19} \mathrm{~F}$-NMR-spectra. The absorption spectra give additional evidence for the structures of Bodipy-porphyrazine conjugates $\mathbf{1}$ and $\mathbf{2}$ as they consist of superimposable absorption features see Fig. 3, S7, and S8† and Table 2.

\section{Free-base porphyrazine}

Recent work has documented that the behavior of free-base porphyrazines upon protonation is easily followed by steady-

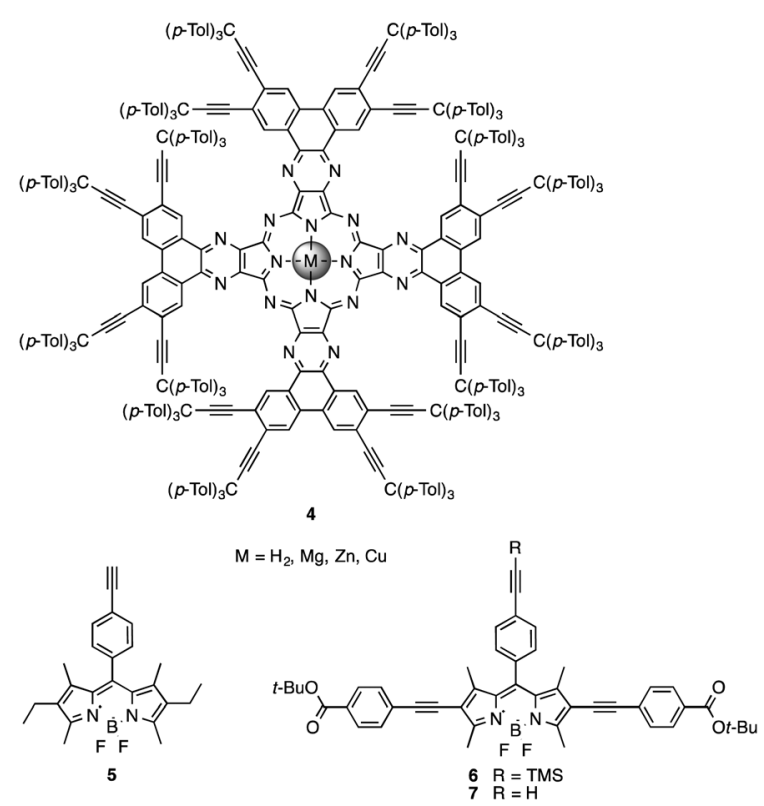

Chart 2 Molecular structures of model compounds 4 to 7. 
state absorption spectroscopy. ${ }^{26,27}$ In particular, changes in the absorption spectrum, especially with respect to shape and position of the long-wavelength Q-band, seem to correlate with the solvent polarity and the protonation of the chromophore. Overall, the electronic transitions are red-shifted and the Q-band is split into two due to the transformation of $D_{4 \mathrm{~h}}$ symmetry into $D_{2 \mathrm{~h}}$ symmetry. ${ }^{26}$ Dissolving, for example, the free-base porphyrazine $\mathbf{4}-\mathbf{H}_{2}$ in toluene gives rise to a broad absorption with a Soret-band at $410 \mathrm{~nm}$ and two Q-band maxima at 713 and $737 \mathrm{~nm}$ resulting from the $D_{2 \mathrm{~h}}$ symmetry. In titration experiments of $\mathbf{4}-\mathbf{H}_{\mathbf{2}}$ with trifluoroacetic acid the two maxima merge into a single broad band at $721 \mathrm{~nm}$ - see Fig. 1 (top). This leads to the assumption of the protonation of all of the azomethine nitrogens in $\mathbf{4}-\mathbf{H}_{2} \cdot{ }^{26}$ Qualitatively, this behavior is reversible: Fig. 1 (bottom) documents a titration experiment of protonated $\mathbf{4}-\mathbf{H}_{\mathbf{2}}$ with triethylamine, leading to
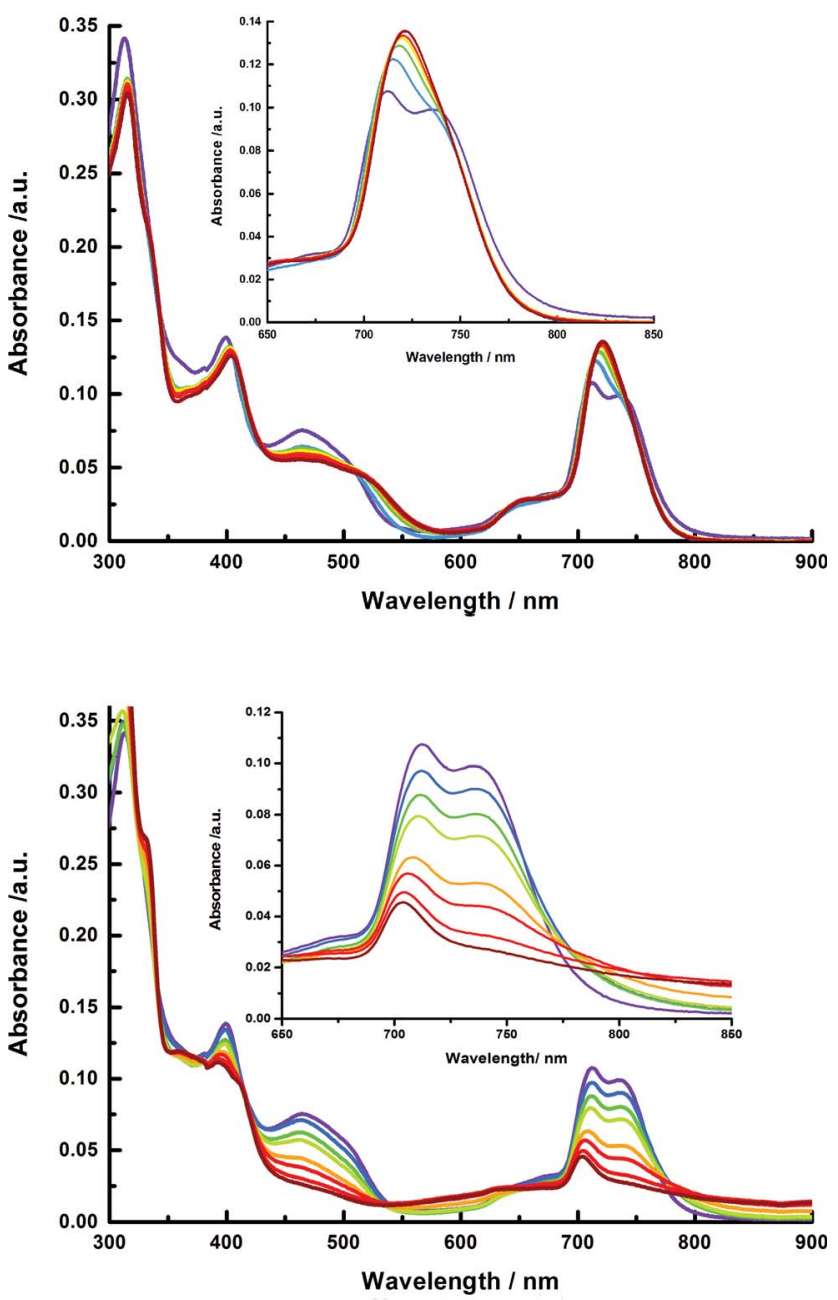

Fig. 1 Absorption spectra of free base porphyrazine $4-\mathrm{H}_{2}$ in toluene at room temperature. Top: titration experiments with successive addition of trifluoroacetic acid (from 0 to $1000 \mu \mathrm{L}$ ) - insert: zoomed in view of the $Q$-bands illustrating the red-shift and the increase of the $Q$-band absorptions at $737 \mathrm{~nm}$. Bottom: titration experiments with successive addition of triethylamine (from 0 to $1000 \mu \mathrm{L}$ ) - insert: zoomed in view of the $Q$-bands illustrating the blue shift and the decrease of the $Q$ bands at $737 \mathrm{~nm}$. the stepwise disappearance of the maximum at $737 \mathrm{~nm}$, which eventually merges into a single band at $703 \mathrm{~nm}$. This strongly corroborates the impact of protonation on free-base porphyrazine. ${ }^{28}$

\section{Metalloporphyrazines}

Electrochemical characterization. The electrochemical properties of $\mathbf{1}, \mathbf{2}, \mathbf{4}, \mathbf{5}$, and $\mathbf{6}$ were investigated by cyclic and square wave voltammetry. The data are reported $v s$. ferrocene/ ferrocenium $\left(\mathrm{Fc} / \mathrm{Fc}^{+}\right)$and are summarized in Table 1. Analyses of the cyclic voltammograms of $\mathbf{4 - M g}, \mathbf{4 - Z n}$, and $\mathbf{4 - C u}$ reveal reversible processes in the reduction range at $-0.99 \mathrm{~V}$ (4-Mg), $-0.96 \mathrm{~V}(\mathbf{4}-\mathbf{Z n})$, and $-0.98 \mathrm{~V}(\mathbf{4}-\mathbf{C u})$. A comparison of all three is shown in Fig. 2. Turning to 5 and $\mathbf{6}$, reversible processes are discernable in the reduction range at $-1.55 \mathrm{~V}$ for 5 as well as at $-0.99 \mathrm{~V}$ for $\mathbf{6}$. The cyclic voltammograms of $\mathbf{1 - M g}$ and $\mathbf{2}-\mathbf{M g}$, which bear covalently linked Bodipys, are shown in Fig. S1. $\dagger$ Overall, the reduction potentials are shifted towards higher potentials relative to $\mathbf{4} \mathbf{- M g}(-0.97 \mathrm{~V})$ as well as lower potentials, namely $-1.33 \mathrm{~V}$, relative to 5 . We note that the Bodipy reduction overlaps with the porphyrazine reduction and, therefore, a more detailed analysis is rather difficult. Similar changes occur in 1Zn and 2-Zn, which are illustrated in Fig. S2. $\dagger$ In the reduction range, the potentials for $\mathbf{4 - Z n}$ are shifted towards lower potentials. The reduction of $\mathbf{1 - C u}$ is affected in the same manner with a reduction of porphyrazine at $-0.935 \mathrm{~V}$ and of Bodipy at -1.31 $\mathrm{V}-$ see Fig. S3.†

Photophysical characterization. The steady-state absorption spectra of 4-Mg feature a characteristically broad spectrum in the UV-visible region, which reaches out to the Q-band at $\lambda_{\max }=$ $707 \mathrm{~nm}$. Changing the metal to either 4-Zn or 4-Cu leads to no appreciable changes at first glance - see Fig. S4. $\dagger$ A closer look at the Q-band reveals, however, slight shifts of about $4 \mathrm{~nm}$ for $\mathbf{4 - Z n}$ $\left(\lambda_{\max }=703 \mathrm{~nm}\right)$ and about $3 \mathrm{~nm}$ for $\mathbf{4}-\mathbf{C u}\left(\lambda_{\max }=704 \mathrm{~nm}\right)$. Table 2 summarizes all of the steady-state absorption data. Please note that when dissolving porphyrazines in coordinating solvents such as THF, strong red shifts up to about $10 \mathrm{~nm}$ are observed. Fig. S5† summarizes the spectra of $\mathbf{4 - M g}$ in different solvents.

Table 1 Redox potentials in the reduction range of 5, 6 and the corresponding 4,1 , and $2 \mathrm{vs}$. $\mathrm{Fc} / \mathrm{Fc}^{+}(0.2 \mathrm{~V})$ in toluene-acetonitrile $(4: 1 \mathrm{v} /$ v) with $0.1 \mathrm{M}$ tetrabutylammonium hexafluorophosphate as a supporting electrolyte

\begin{tabular}{lll}
\hline & $E_{1 / 2}$ porphyrazine & $E_{1 / 2}$ Bodipy \\
\hline $\mathbf{5}$ & & -1.545 \\
$\mathbf{6}$ & & -0.945 \\
$\mathbf{4}-\mathbf{Z n}$ & -0.96 & \\
$\mathbf{1}-\mathbf{Z n}$ & -0.81 & -1.41 \\
$\mathbf{2}-\mathbf{Z n}$ & -0.65 & -1.14 \\
$\mathbf{4 - M g}$ & -0.985 & \\
$\mathbf{1}-\mathbf{M g}$ & -0.97 & -1.33 \\
$\mathbf{2}-\mathbf{M g}$ & -0.975 & - \\
$\mathbf{4 - C u}$ & -0.97 & \\
$\mathbf{1}-\mathbf{C u}$ & -0.935 & -1.31 \\
$\mathbf{2}-\mathbf{C u}$ & -0.945 & -
\end{tabular}




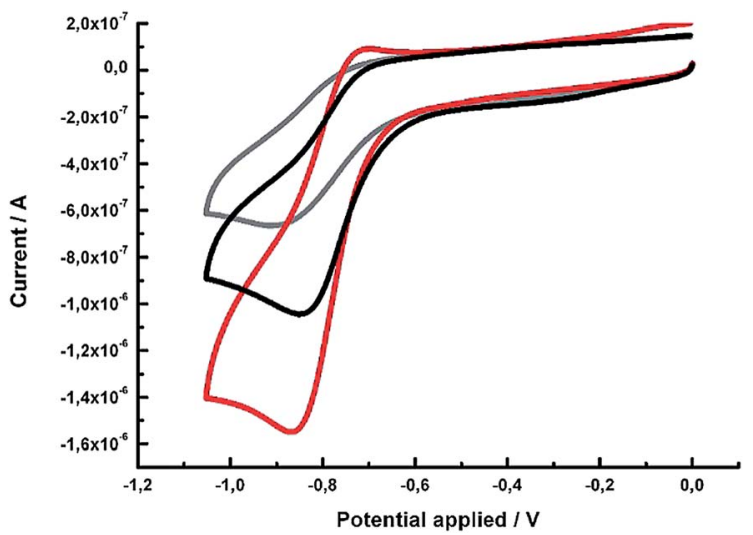

Fig. 2 Cyclic voltammograms of 4-Cu (black), 4-Mg (red), and 4-Zn (grey), measured at room temperature in degassed toluene-acetonitrile $(4: 1 \mathrm{v} / \mathrm{v})$ with $0.1 \mathrm{M}$ tetrabutylammonium hexafluorophosphate as a supporting electrolyte.

Table 2 Summary of steady-state spectroscopic data of porphyrazines 1, 2 and 4, and Bodipys 5 and 6 measured in toluene

\begin{tabular}{|c|c|c|c|c|}
\hline & \multirow{2}{*}{$\frac{\text { Absorption }}{\lambda_{\max } / \mathrm{nm}\left(\varepsilon / \mathrm{mol}^{-1} \mathrm{~cm}^{-1}\right)}$} & \multicolumn{3}{|c|}{ Fluorescence } \\
\hline & & $\lambda_{\max } / \mathrm{nm}$ & $\varphi$ & $\tau / \mathrm{ns}$ \\
\hline \multicolumn{5}{|c|}{$\lambda_{\mathrm{ex}}=680 \mathrm{~nm}$} \\
\hline $4-\mathrm{Zn}$ & 703 (136 192) & 710 & 0.2 & 1.92 \\
\hline $1-\mathrm{Zn}$ & 706 (111 960) & 710 & 0.12 & 1.91 \\
\hline 2-Zn & 706 (111 307) & 710 & 0.08 & 1.27 \\
\hline $4-M g$ & 707 (147 013) & 710 & 0.19 & 4.95 \\
\hline 1-Mg & $707(64100)$ & 710 & 0.06 & 5.26 \\
\hline 2-Mg & 707 (95 947) & 710 & 0.013 & 5.73 \\
\hline 4-Cu & $704(238240)$ & - & - & - \\
\hline 1-Cu & 711 (114 078) & - & - & - \\
\hline 2-Cu & $711\left(\begin{array}{ll}6 & 095)\end{array}\right.$ & - & - & - \\
\hline \multicolumn{5}{|c|}{$\lambda_{\mathrm{ex}}=520 \mathrm{~nm}$} \\
\hline 5 & $528(86929)$ & 550 & 0.69 & 5.39 \\
\hline 1-Zn & $528(335827)$ & 550 & 0.091 & - \\
\hline 1-Zn & & 710 & 0.019 & - \\
\hline 1-Mg & 528 (316 158) & 550 & 0.044 & - \\
\hline $1-\mathrm{Mg}$ & & 710 & 0.008 & - \\
\hline $1-\mathrm{Cu}$ & $528(510565)$ & 550 & 0.026 & - \\
\hline 1-Cu & & 710 & - & - \\
\hline \multicolumn{5}{|c|}{$\lambda_{\mathrm{ex}}=560 \mathrm{~nm}$} \\
\hline 6 & $580(65913)$ & 600 & 0.54 & 3.74 \\
\hline $2-\mathrm{Zn}$ & $580(342248)$ & 600 & 0.098 & 4.03 \\
\hline $2-\mathrm{Zn}$ & & 710 & 0.021 & - \\
\hline $2-\mathrm{Mg}$ & 580 (330 977) & 600 & 0.038 & 3.78 \\
\hline $2-\mathrm{Mg}$ & & 710 & 0.025 & - \\
\hline $2-\mathrm{Cu}$ & $580(200782)$ & 600 & 0.015 & 3.15 \\
\hline 2-Cu & & 710 & - & - \\
\hline \multicolumn{5}{|c|}{$\lambda_{\mathrm{ex}}=410 \mathrm{~nm}$} \\
\hline $4-\mathrm{Zn}$ & 703 (136 192) & 475 & 0.058 & - \\
\hline 4-Mg & 707 (147 013) & 475 & 0.008 & - \\
\hline $4-\mathrm{Cu}$ & $704(238240)$ & 480 & 0.002 & - \\
\hline
\end{tabular}

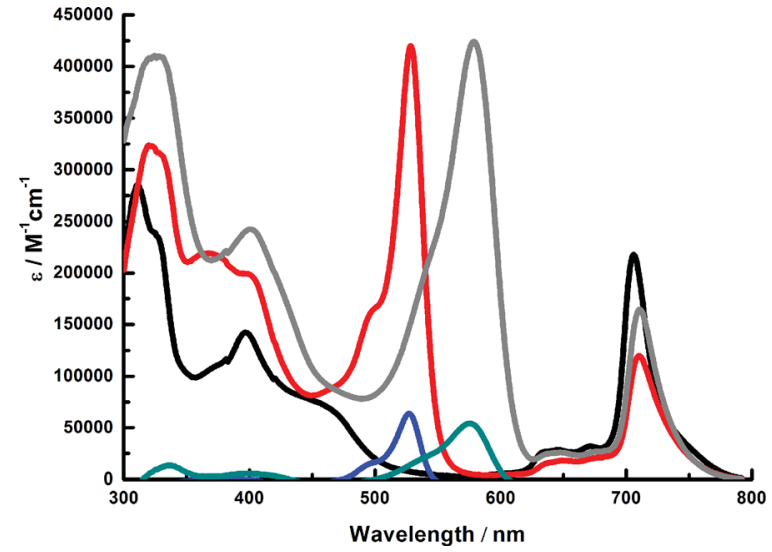

Fig. 3 Absorption spectra in the visible region of 5 (blue), 6 (dark cyan), 4-Mg (black), 1-Mg (red), and 2-Mg (grey) in toluene at room temperature.

The characteristic steady-state absorption features of $\mathbf{5}$ and $\mathbf{6}$ are derived from Fig. S6, $\uparrow$ with weak absorptions in the UV region and strong absorption maxima at 528 and $580 \mathrm{~nm}$. The absorptions of 1-Mg and 2-Mg are depicted in Fig. 3. The visible region is dominated by a broad absorption stemming from the porphyrazine followed by the characteristic features of the corresponding Bodipy, before the Q-band of the porphyrazine sets in. 1-Zn and 2-Zn show the same features, with the only exception that the Q-band maximum appears at $703 \mathrm{~nm}$ - see Fig. S7. $\dagger$ Examples for 1-Cu and 2-Cu are shown in Fig. S8 $\dagger$ and they, too, resemble those of the individual constituents. With these data in hand, it is safe to assume that interactions between Bodipy substituents and porphyrazine in the ground state are negligible.

In parallel, the excited state properties were derived from fluorescence measurements. Table 2 summarizes the excited state properties. When exciting the Soret-band of 4 at $410 \mathrm{~nm}$, a rather strong second singlet excited state fluorescence, namely S2, with $475 \mathrm{~nm}$ maxima for 4-Mg and 4-Zn and a $480 \mathrm{~nm}$ maximum for 4-Cu is observed - see Fig. S9. $\dagger$ For these, fluorescence quantum yields of 0.008 (4-Mg), 0.058 (4-Zn), and 0.002 (4-Cu) were calculated. Furthermore, strong S1 fluorescence is detected at $710 \mathrm{~nm}$ for $\mathbf{4 - Z n}$ and $\mathbf{4 - M g}$. In contrast, 4-Cu lacks any fluorescence in this range - see Fig. S10. $\dagger$ When exciting the Q-band of $\mathbf{4 - M g}$ and $\mathbf{4 - Z n}$ at $680 \mathrm{~nm}$, fluorescence quantum yields of 0.19 and 0.2 with fluorescence lifetimes of 4.9 and 1.9 ns are determined using a zinc phthalocyanine as reference $(0.3$ and 3.1 ns in toluene) ${ }^{\mathbf{2 6}}$ (Fig. S11 and S12 $\dagger$ ).

To get further insights into the fluorescent behaviour of $\mathbf{5}$, the latter is excited at $520 \mathrm{~nm}$ and from the fluorescence at 550 $\mathrm{nm}$ a quantum yield of 0.69 and lifetime of $5.3 \mathrm{~ns}$ were determined. Similarly, for 6, which was excited at $560 \mathrm{~nm}$, a fluorescence at $600 \mathrm{~nm}$ developed with a quantum yield of 0.54 and a lifetime of $3.7 \mathrm{~ns}$.

Next, we turned to 1-Mg and 2-Mg, which were excited at 410 $\mathrm{nm}$ - see Fig. 4. The fluorescence from S2 of the porphyrazine is replaced with Bodipy-centered fluorescence at 550 and $600 \mathrm{~nm}$, respectively. As such, we postulate an energy transfer in $\mathbf{1 - M g}$ 


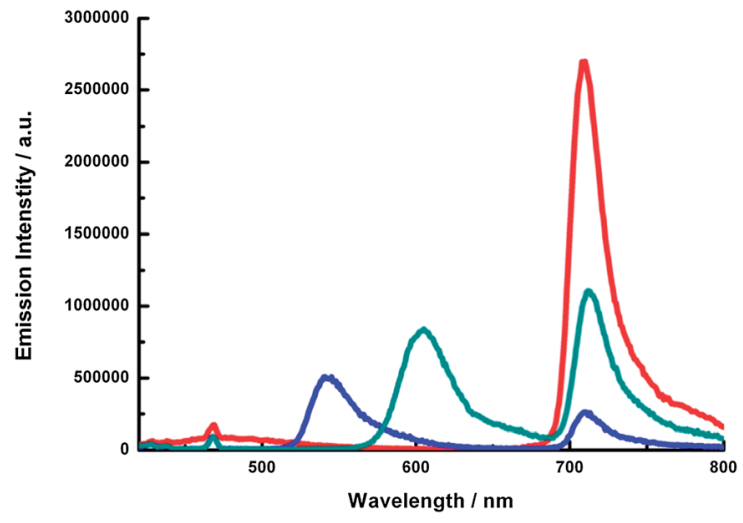

Fig. 4 Room temperature fluorescence spectra in the visible region of 4-Mg (red), 1-Mg (blue), and 2-Mg (dark cyan) measured in toluene with solutions that exhibit the same optical absorbance of 0.01 at a 410 $\mathrm{nm}$ excitation wavelength.

and 2-Mg from the higher singlet excited states, S2 and higher, of the porphyrazines to either Bodipy. Corroboration for this hypothesis came from the excitation spectra of the fluorescence at 550 and $600 \mathrm{~nm}$, respectively - see Fig. S15. $\dagger$ Here, the porphyrazine characteristics are discernable through the visible range. Nevertheless, the energetically lower lying S1 fluorescence of 1-Mg and 2-Mg evolved in the region around $700 \mathrm{~nm}$.

Fig. S16 $†$ shows the fluorescence spectra of 5 and 1-Mg upon photoexcitation at $520 \mathrm{~nm}$. In the case of 1-Mg the Bodipycentered fluorescence is quenched by up to $93.6 \%$, when compared to the model compound 5, leading to a quantum yield of only 0.044 . It is important to note that fluorescence evolves at $710 \mathrm{~nm}$, which is assigned to the intrinsic fluorescence of the porphyrazine core. Here, an energy transfer takes place from Bodipy to porphyrazine with an efficiency of almost 0.8 . This trend is also notable for $\mathbf{1 - C u}$ and $\mathbf{1 - Z n}$, as summarized in Table 2. By the same token, energy transfer occurs when exciting the Bodipy in 2-Mg at $560 \mathrm{~nm}$. For example, the fluorescence features a maximum at $600 \mathrm{~nm}$, which is, however,

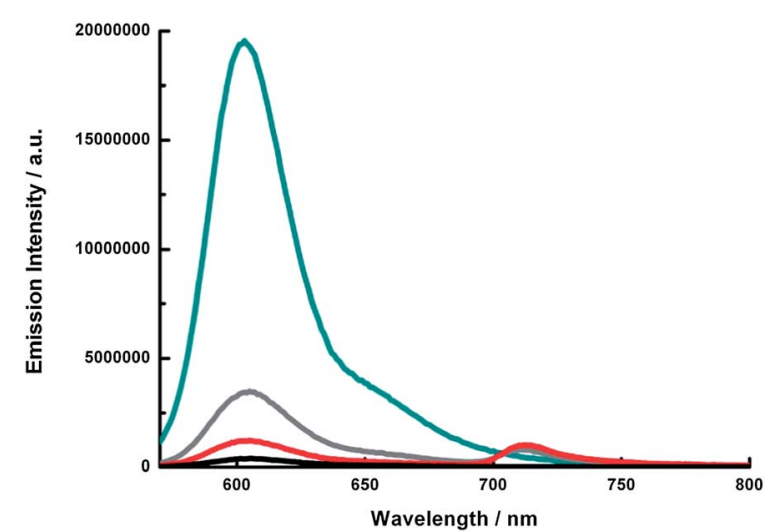

Fig. 5 Room temperature fluorescence spectra in the visible region of 6 (dark cyan), 2-Cu (black), 2-Mg (red), and 2-Zn (grey) measured in toluene with solutions that exhibit the same optical absorbance of 0.01 at a $560 \mathrm{~nm}$ excitation wavelength. quenched by $92.9 \%$ when compared to 6 only - see Fig. 5. As a consequence, the overall quantum yields decrease from 0.54 to 0.038. Again, an additional characteristic fluorescence appeared in the Q-band range at $710 \mathrm{~nm}$. This corroborates an energy transfer in 2-Mg from the peripheral Bodipy to the porphyrazine core with a $25 \%$ efficiency. Additional details are derived from the time resolved emission spectra, which are displayed in Fig. S17-S21† and summarized in Table S2. $\dagger$

Fluorescence quantum yields were determined as 0.06 (1$\mathbf{M g}$ ) and $0.01(2-\mathbf{M g})$ upon excitation at $680 \mathrm{~nm}$ in each case. The

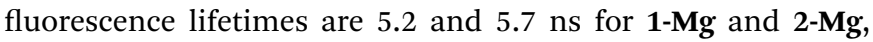
respectively. By the same token, quantum yields of 0.12 and 0.08 as well as lifetimes of 1.9 and $1.2 \mathrm{~ns}$ are established for $\mathbf{1 - Z n}$ and 2-Zn, respectively - Fig. S13. $\dagger$

For the porphyrazines 1-Cu and 2-Cu, an energy transfer from the $\mathrm{S} 2$ to the corresponding Bodipy takes place and is depicted in Fig. S14, $\dagger$ but no fluorescence in the Q-band region is detected. To gain further insight into the fluorescence behaviour, fluorescence spectroscopy in the near-IR was performed, as illustrated in Fig. 6. In addition to the fine structure of the intrinsic fluorescence for $\mathbf{4}-\mathbf{M g}$ and $\mathbf{4 - Z n}$, weak spinforbidden phosphorescence evolves for $\mathbf{4 - C u}$ with maxima at 1068, 1165, and $1228 \mathrm{~nm}$.

Femtosecond transient absorption spectroscopy was used to obtain further insights into the excited state interactions in $\mathbf{1}$ and 2 and to corroborate the proposed energy transfer processes. To this end, 1, 2, 4, 5, and 6 were probed with 387, 530 , and $695 \mathrm{~nm}$ excitation.

In the case of $\mathbf{4 - M g}$, the singlet excited state - formed essentially right after the laser pulse - induces a net decrease of the absorptions at 506, 623, and $705 \mathrm{~nm}$, regions which are dominated by strong 4-Mg ground state absorptions - see Fig. 7. This suggests consumption of $\mathbf{4 - M g}$ as a result of converting its singlet ground state to the corresponding singlet excited state. An immediately formed absorption accompanies the transient bleaching. For example, the $\mathbf{4 - M g}$ based singlet excited state exhibits new absorption bands at 833 and $914 \mathrm{~nm}$. The singlet transients produced upon 695 photoexcitation decay with

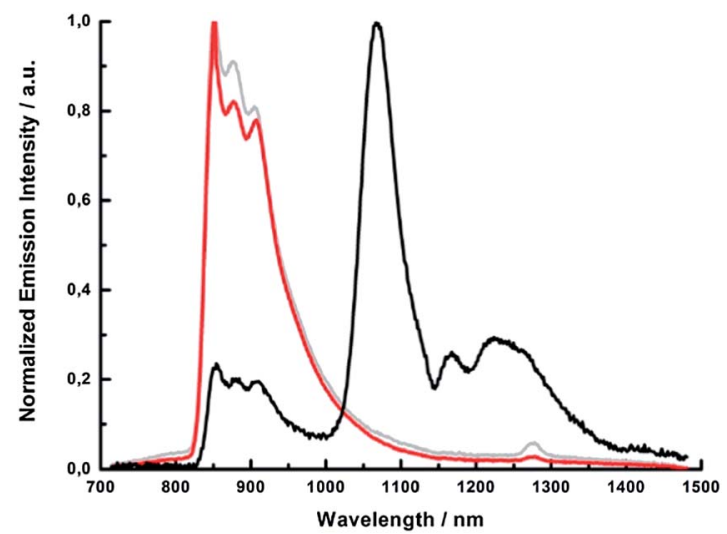

Fig. 6 Normalized room temperature fluorescence spectra in the NIR region of $4-\mathrm{Cu}$ (black), 4-Mg (red), and 4-Zn (grey), in toluene with solutions that exhibit the same concentration $\left(1 \times 10^{-6} \mathrm{M}\right)$ at a $685 \mathrm{~nm}$ excitation wavelength. 


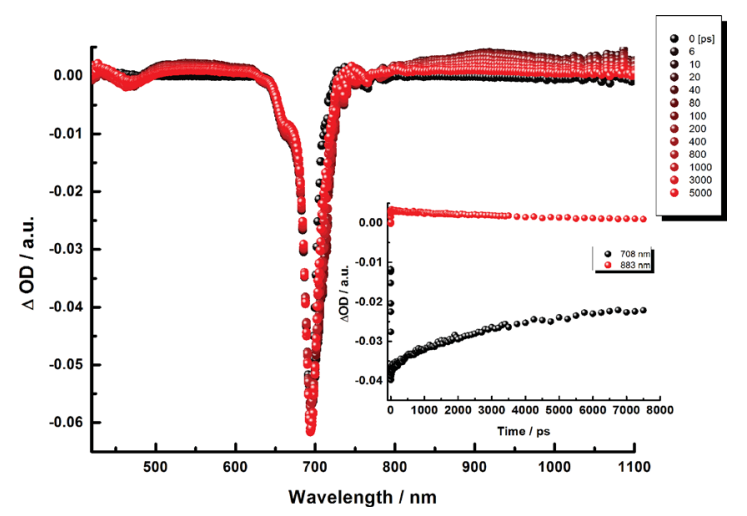

Fig. 7 Differential absorption spectra (visible and near-infrared) obtained upon femtosecond flash photolysis (695 nm and $200 \mathrm{~nJ}$ ) of $4-\mathrm{Mg}$ in toluene with several time delays between 0 and 8000 ps at room temperature. Insert - time-absorption profiles of the spectra at 710 and $900 \mathrm{~nm}$, monitoring the intersystem crossing dynamics (i.e. $4.9 \pm 0.4 \mathrm{ps})$.

lifetimes of $4.9 \pm 0.4 \mathrm{~ns}$ via intersystem crossing to the corresponding triplet manifold. Similar behavior is observed when 4Zn and 4-Cu - see Fig. S22 and S23†- are excited at $695 \mathrm{~nm}$. In the case of 4-Zn new absorption bands emerge at 535 and 910 $\mathrm{nm}$, while the intersystem crossing to the triplet manifold features a lifetime of $1.6 \pm 0.1$ ns. Finally, for 4-Cu new absorption features evolve at 430 and $900 \mathrm{~nm}$, from which a short lifetime of $0.48 \pm 0.08 \mathrm{ps}$ is derived, followed by an intersystem crossing to the corresponding long lived triplet manifold.

The corresponding femtosecond experiments with 5 and $\mathbf{6}$ reveal the instantaneous formation of the singlet excited state features upon $530 \mathrm{~nm}$ laser excitation - see Fig. S24 and S25. $\dagger$ Here, the transient absorption spectra are dominated by strong bleaching between 450 and $650 \mathrm{~nm}$ for 5 and between 500 and $700 \mathrm{~nm}$ for 6 . The latter are due to the depletion of the singlet ground states and the concurring population of the singlet excited states. In the 400 to $500 \mathrm{~nm}$ and the 1000 to $1200 \mathrm{~nm}$ regions, additional maxima emerge. Overall, all of the aforementioned singlet excited state features are long-lived with lifetimes of $4.8 \pm 0.2(5)$ and $0.9 \pm 0.1 \mathrm{~ns}(6)$ and implicate a slow intersystem crossing to the corresponding triplet manifolds.

The spectral features of $\mathbf{1 - M g}$ around 1 ps upon excitation at $530 \mathrm{~nm}$ are almost identical with those recorded for the singlet excited state of $\mathbf{5}$ - see Fig. 8. The lifetime of the latter is, however, impacted by the presence of the covalently attached porphyrazine. Formation of a new transient develops as a result of the rapid decay (i.e. $5.8 \pm 0.2 \mathrm{ps}$ ) of the Bodipy singlet excited state. This, in fact, replaces in 1-Mg the much slower intersystem crossing to the triplet excited state noted in 5. Importantly, the new transient resembles the singlet excited state characteristics of $\mathbf{4 - M g}$, that is, maxima at 428 and $914 \mathrm{~nm}$ as well as minima at 497, 632, and $705 \mathrm{~nm}$. This suggests involvement of the singlet excited state of porphyrazine in an intramolecular energy transfer, as it occurs between the photoexcited Bodipy and the singlet ground state of the porphyrazine.

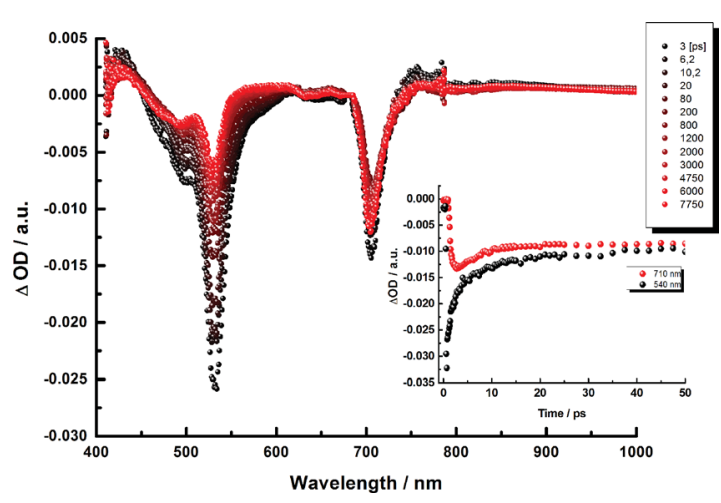

Fig. 8 Differential absorption spectra (visible and near-infrared) obtained upon femtosecond flash photolysis (530 nm and $200 \mathrm{~nJ}$ ) of $1-\mathrm{Mg}$ in toluene with several time delays between 0 and 8000 ps at room temperature. Insert - time-absorption profiles of the spectra at 520 and $710 \mathrm{~nm}$, monitoring the intramolecular energy transfer dynamics (i.e. $5.8 \pm 0.2 \mathrm{ps}$ ).

Likewise, upon exciting 2-Mg at $530 \mathrm{~nm}$, the Bodipy singlet excited state features are seen early on, namely after 1 ps - see

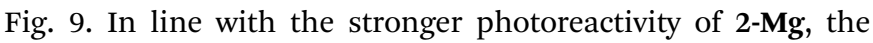
Bodipy singlet excited state decays much faster with $5.5 \pm 0.3 \mathrm{ps}$ in the presence of the porphyrazine than in 1-Mg. Importantly, maxima at $910 \mathrm{~nm}$ as well as minima at 497, 631, and $705 \mathrm{~nm}$ as they evolve simultaneously with the Bodipy singlet excited state decay are exact matches of the porphyrazine singlet excite state and, in turn, confirm the transduction of singlet excited state energy.

Turning to the $530 \mathrm{~nm}$ excitation of $\mathbf{1 - Z n}$, again the singlet excited state features of Bodipy are formed immediately after excitation and are accompanied by a strong ground state bleaching - see Fig. S26. $\uparrow$ The latter then decays with $8.7 \pm 1.4$ ps. The transduction of singlet excited state energy was confirmed by detecting maxima at $900 \mathrm{~nm}$ as well as minima at 475,635 , and $705 \mathrm{~nm}$, which are exact matches of what has been seen for the $\mathbf{4 - Z n}$ singlet excited state. In $\mathbf{2}-\mathbf{Z n}$, a new transient

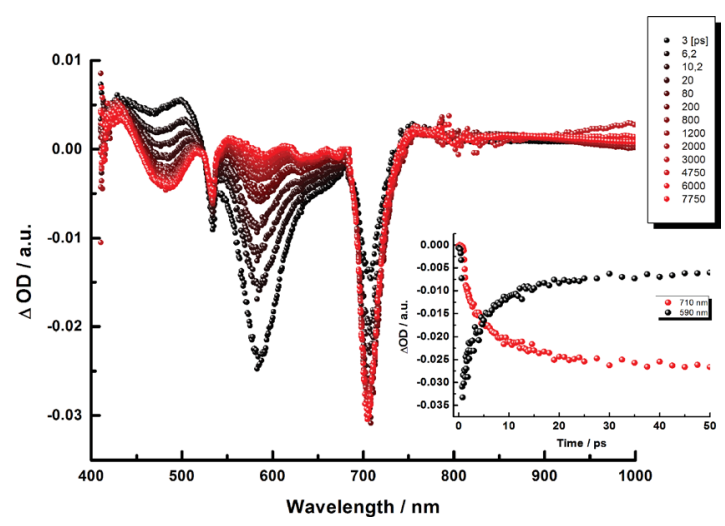

Fig. 9 Differential absorption spectra (visible and near-infrared) obtained upon femtosecond flash photolysis (530 nm and $200 \mathrm{~nJ}$ ) of $2-\mathrm{Mg}$ in toluene with several time delays between 0 and 8000 ps at room temperature. Insert - time-absorption profiles of the spectra at 590 and $710 \mathrm{~nm}$, monitoring the intramolecular energy transfer dynamics (i.e. $5.5 \pm 0.3 \mathrm{ps}$ ). 


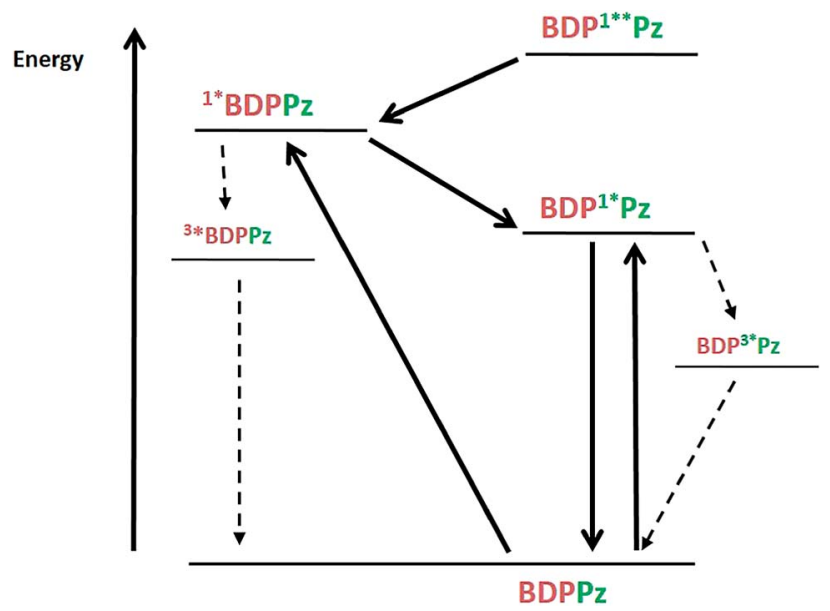

Fig. 10 Energy diagrams illustrating the intramolecular energy transfer processes of the different light harvesting Bodipy-porphyrazine conjugates.

develops as a result of the rapid decay $(2.5 \pm 0.2 \mathrm{ps})$ of the Bodipy singlet excited state, which replaces the much slower intersystem crossing to the triplet excited state - Fig. S27. $\uparrow$ The newly formed transient resembles the singlet excited state characteristics of $\mathbf{4 - Z n}$, that is, maxima at 535 and $910 \mathrm{~nm}$ as well as minima at 475, 635, and $705 \mathrm{~nm}$. Again, we hypothesize that an intramolecular energy transfer takes place between the photoexcited Bodipy and the porphyrazine in $\mathbf{2 - Z n}$.

Fig. S28† shows the differential absorption changes recorded upon $530 \mathrm{~nm}$ excitation of 1-Cu. In 1-Cu, the singlet excited state of Bodipy decays, however, rather slowly with a lifetime of $4.4 \pm 0.5 \mathrm{ps}$. At the end of this process, maxima at 430 and 900 $\mathrm{nm}$ as well as minima at 495, 635, and $705 \mathrm{~nm}$ are noted. All of the aforementioned match those noted upon the photoexcitation of 4-Cu. This is taken as evidence in support for the transduction of singlet excited state energy. On a longer timescale, the fate of the porphyrazine-based singlet excited state is identical to what is seen for 4-Cu. In this regard, a fast intersystem crossing, driven by a strong spin-orbit coupling, governs the rapid transformation of the singlet into the triplet excited state. Very similarly, in $530 \mathrm{~nm}$ excitation experiments with 2$\mathrm{Cu}$ the singlet excited state of Bodipy features evolve right after the conclusion of the excitation - see Fig. S29. $\dagger$ A new transient develops as a result of the rapid decay (i.e. $5.3 \pm 0.3 \mathrm{ps}$ ) of the Bodipy-based singlet excited state. In fact, the latter replaces the intersystem crossing to the triplet excited state, in 2-Cu with the singlet excited state characteristics seen for the reference, namely 4-Cu. Notable here are maxima at 430 and $900 \mathrm{~nm}$ as well as minima at 495, 635, and $705 \mathrm{~nm}$. The aforementioned corroborate that in 1-Cu and 2-Cu an energy transfer prevails between the Bodipys and the porphyrazine fragments.

In reference experiments, 4, 5 and $\mathbf{6}$ were excited at $387 \mathrm{~nm}$. However, due to the dominating absorptions of the porphyrazines at the $387 \mathrm{~nm}$ excitation wavelength, no appreciable Bodipy features were seen at any time following the excitation. Instead, only the porphyrazines characteristics emerge - vide supra.

\section{Conclusions}

A novel set of porphyrazines was designed, synthesized, and probed with respect to panchromatic light harvesting. On one hand, zinc, copper, or magnesium ions were complexed by porphyrazines to tune their ground and excited state features. On the other hand, up to eight Bodipys were covalently attached to the periphery of the porphyrazines to enhance the ground state absorption. As such, we realized broad absorption cross sections throughout most of the visible range and excited state energy funnelling in the corresponding star-shaped conjugates. Fig. 10 gives an illustrative example of the photophysical processes corroborated in measurements based on time-resolved fluorescence and femtosecond transient absorption spectroscopy. From the latter we derive the lack of ground state interactions, but strong intramolecular interactions in the excited state. Spectroscopic and kinetic evidence support a fast and unidirectional singlet excited state energy transfer from the photoexcited Bodipys at the periphery to the porphyrazines at the core upon visible light excitation from 450 to $650 \mathrm{~nm}$. To this end, singlet excited state lifetimes of 8.7 and $5.8 \mathrm{ps}$ for $\mathbf{1 - Z n}$ and $\mathbf{1 - M g}$, respectively, and 2.5 and 5.5 ps for $2-\mathbf{Z n}$ and $2-\mathbf{M g}$, respectively, were determined and reflect the exergonic energy transfer $(\sim 1.7$ $\mathrm{eV}$ ). From the aforementioned we established the following order of energy transfer rates 1-Zn $<\mathbf{2 - M g}<\mathbf{1 - M g}<\mathbf{2 - Z n}$. A better spectral and orbital overlap between the Bodipys and the porphyrazines is a likely reason for this trend. Once the transduction of singlet excited state energy is concluded a porphyrazinecentered intersystem crossing to the corresponding triplet excited states evolves prior to the repopulation of the singlet ground state. This photoreactivity changes slightly, however, upon excitation in the 350 to $450 \mathrm{~nm}$ range. Notably, in this range higher lying singlet excited states of the porphyrazines are formed, which are the beginning of an energy transfer pingpong, that is, from the higher lying singlet excited states of the porphyrazines $(\sim 2.8 \mathrm{eV})$ to the singlet excited states of Bodipys $(\sim 2.6 \mathrm{eV})$ and back to the porphyrazines $(\sim 1.7 \mathrm{eV})$, but to their singlet excited states. $\mathbf{1 - C u}$ and $\mathbf{2 - C u}$ react differently, owing to the fact that a heavy atom effect facilitates a fast intersystem crossing within a few hundredths of picoseconds. The impact of overlapping orbitals of Bodipy and metalloporphyrazine is clearly demonstrated, rendering the title compounds promising candidates in the design of panchromatic light harvesting systems for artificial photosynthesis by different combinations of antenna and basic chromophore moieties.

\section{Acknowledgements}

V.E. acknowledges a fellowship from the Studienstiftung des deutschen Volkes. D.M.G. acknowledges funding from the Bavarian Initiative "SolTech". S.K. acknowledges funding from Cluster of Excellence "Engineering of Advanced Materials".

\section{Notes and references}

1 D. Gust, T. A. Moore and A. L. Moore, Acc. Chem. Res., 2009, 42, 1890; G. F. Moore, M. Hambourger, M. Gervaldo, 
O. G. Poluektov, T. Rajh, D. Gust, T. A. Moore and A. L. Moore, J. Am. Chem. Soc., 2008, 130, 10466; M. R. Wasielewski, Acc. Chem. Res., 2009, 42, 1910; R. Carmieli, Q. Mi, A. B. Ricks, E. M. Giacobbe, S. M. Mickley and M. R. Wasielewski, J. Am. Chem. Soc., 2009, 131, 8372; S. Fukuzumi, Phys. Chem. Chem. Phys., 2008, 10, 2283.

2 A. Hagfeldt, G. Boschloo, L. Sun, L. Kloo and H. Pettersson, Chem. Rev., 2010, 110, 6595; D. Gust, T. A. Moore and A. L. Moore, Chem. Commun., 2006, 1169; V. Balzani, A. Credi and M. Venturi, Chem.-Eur. J., 2008, 14, 26; K. E. Splan, M. H. Keefe, A. M. Massari, K. A. Walters and J. T. Hupp, Inorg. Chem., 2002, 41, 619; A. Ambroise, C. Kirmaier, R. W. Wagner, R. S. Loewe, D. F. Bocian, D. Holten and J. S. Lindsey, J. Org. Chem., 2002, 67, 3811.

3 V. Balzani, A. Credi and M. Venturi, ChemSusChem, 2008, 1, 26; S. Fukuzumi, Eur. J. Inorg. Chem., 2008, 1351; J. E. Bullock, R. Carmieli, S. M. Mickley, J. Vura-Weis and M. R. Wasielewski, J. Am. Chem. Soc., 2009, 131, 11919.

4 M. V. Martínez-Díaz and T. Torres, in Handbook of Porphyrin Science, ed. K. M. Kadish, K. M. Smith and R. Guilard, World Scientific Publishing Company, 2010, vol. 10, ch. 45; S. Fukuzumi, in Handbook of Porphyrin Science, ed. K. M. Kadish, K. M. Smith and R. Guilard, World Scientific Publishing Company, 2010, vol. 10, ch. 46 and related chapters therein.

5 D. Gust, T. A. Moore and A. L. Moore, Acc. Chem. Res., 1993, 26, 198; D. Gust and T. A. Moore, in The Porphyrin Handbook, ed. K. M. Kadish, K. Smith and R. Guilard, Academic Press, San Diego, 2000, vol. 8, p. 153; S. Fukuzumi and D. M. Guldi, in Electron Transfer in Chemistry, ed. V. Balzani, Wiley-VCH, Weinheim, 2001, vol. 2, p. 270; S. Fukuzumi, in The Porphyrin Handbook, ed. K. M. Kadish, K. Smith and R. Guilard, Academic Press, San Diego, 2000, vol. 8, p. 115; H. Imahori, K. Tamaki, Y. Araki, Y. Sekiguchi, O. Ito, Y. Sakata and S. Fukuzumi, J. Am. Chem. Soc., 2002, 124, 5165; T. Umeyama and H. Imahori, Energy Environ. Sci., 2008, 1, 120.

6 V. Sgobba and D. M. Guldi, Chem. Soc. Rev., 2009, 38, 165; A. Mateo-Alonso, D. M. Guldi, F. Paolucci and M. Prato, Angew. Chem., Int. Ed., 2007, 46, 8120; L. Sánchez, M. Nazario and D. M. Guldi, Angew. Chem., Int. Ed., 2005, 44, 5374 .

7 J. S. Sessler, B. Wang, S. L. Springs and C. T. Brown, in Comprehensive Supramolecular Chemistry, ed. J. L. Atwood, J. E. D. Davies, D. D. MacNicol and F. Vögtle, Pergamon, 1996, ch. 9.

8 M. E. El-Khouly, O. Ito, P. M. Smith and F. D'Souza, $J$. Photochem. Photobiol., C, 2004, 5, 79; F. D'Souza and O. Ito, Coord. Chem. Rev., 2005, 249, 1410; R. Chitta and F. D'Souza, J. Mater. Chem., 2008, 18, 1440; F. D'Souza and O. Ito, Chem. Commun., 2009, 49, 13.

9 Structure and Bonding, Functional Phthalocyanine Molecular Materials, ed J. Jiang, Springer Verlag, Berlin Heidelberg, 2010, vol. 135, p. 229; G. Bottari, G. de la Torre, D. M. Guldi and T. Torres, Chem. Rev., 2010, 110, 6768; M. Martínez-Díaz, M. Ince and T. Torres, Monatsh. Chem.,
2011, 1; M. V. Martínez-Díaz, G. de la Torre and T. Torres, Chem. Commun., 2010, 46, 7090; I. Radivojevic, A. Varotto, C. Farley and C. M. Drain, Energy Environ. Sci., 2010, 3, 1897; M. G. Walter, A. B. Rudine and C. C. Wamser, J. Porphyrins Phthalocyanines, 2010, 14, 759.

10 S. Mori, M. Nagata, Y. Nakahata, K. Yasuta, R. Goto, M. Kimura and M. Taya, J. Am. Chem. Soc., 2010, 132, 4054; P. Y. Reddy, L. Giribabu, C. Lyness, H. J. Snaith, C. Vijaykumar, M. Chandrasekharam, M. Lakshmikantam, J.-H. Yum, K. Kalyanasundaram, M. Grätzel and M. K. Nazeeruddin, Angew. Chem., 2007, 119, 377; Angew. Chem., Int. Ed., 2007, 46, 373.

11 M. J. Fuchter, C. Zhong, H. Zong, B. M. Hoffman and A. G. Barrett, Aust. J. Chem., 2008, 61, 235.

12 P. A. Stuzhin and C. Ercolani, in The Porphyrin Hand book, ed. K. M. Kadish, K. M. Smith and R. Guilard, Academic Press, 2003, vol. 15; S. L. Michel, S. Baum, A. G. Barrett, B. M. Hoffman, in Progress in inorganic chemistry, ed. Karlin K. D., Wiley, 2001, vol. 50.

13 C. Feucht, T. Linssen and M. Hanack, Chem. Ber., 1994, 127, 113.

14 Phthalocyanines: Properties and Applications, ed. Leznoff C. C. and Lever A. B. P., VCH, New York, 1989-1996, vol. 1-4.

15 A. Loudet and K. Burgess, Chem. Rev., 2007, 107, 4891; G. Ulrich, R. Ziessel and A. Harriman, Angew. Chem., 2008, 120, 1202; Angew. Chem., Int. Ed., 2008, 47, 1184.

16 F. D'Souza, P. M. Smith, M. E. Zandler, A. L. McCarty, M. Itou, Y. Araki and O. Ito, J. Am. Chem. Soc., 2004, 126, 7898.

17 F. D'Souza, S. Gadde, D. J. S. Islam, C. A. Wijesinghe, A. L. Schumacher, M. E. Zandler, Y. Araki and O. Ito, J. Phys. Chem. A, 2007, 111, 8552.

18 A. Loudet and K. Burgess, Chem. Rev., 2007, 107, 4891; F. Li, S. I. Yang, T. Ciringh, J. Seth, C. H. Martin, III, D. L. Singh, D. Kim, R. R. Birge, D. F. Bocian, D. Holten and J. S. Lindsey, J. Am. Chem. Soc., 1998, 120, 10001.

19 E. Maligaspe, T. Kumpulainen, N. K. Subbaiyan, M. E. Zandler, H. Lemmetyinen, N. V. Tkachenko and F. D'Souza, Phys. Chem. Chem. Phys., 2010, 12, 7434.

20 Y. Rio, W. Seitz, A. Gouloumis, P. Vzquez, J. L. Sessler, D. M. Guldi and T. Torres, Chem.-Eur. J., 2010, 16, 1929.

21 J.-Y. Liu, M. E. El-Knhouly, S. Fukuzumi and D. K. P. Ng, Chem.-Eur. J., 2011, 17, 1605.

22 E. Maligaspe, N. Tkacenko, N. K. Subbaiyan, R. Chitta, M. E. Zandler, H. Lemmetyinen and F. D'Souza, J. Phys. Chem. A, 2009, 113, 8478.

23 T. Lazarides, G. Charalambidis, A. Vuillamy, S. Kuhri, D. M. Guldi and A. G. Coutsolelos, Inorg. Chem., 2011, 50(18), 8926.

24 V. Engelhardt, S. Kuhri, J. Fleischhauer, M. Gracía-Iglesias, D. Gonzáles-Rodríguez, G. Bottari, T. Torres, D. M. Guldi and R. Faust, Chem. Sci., 2013, 4(10), 3888.

25 G. Ulrich and R. Ziessel, J. Org. Chem., 2070, 2004, 69; T. K. Khan, M. Broring, S. Mathur and M. Ravikanth, Coord. Chem. Rev., 2013, 257, 2348.

26 P. Petrik, P. Zimick, K. Kopecky, Z. Musil, M. Miletin and V. Loukotova, J. Porphyrins Phthalocyanines, 2007, 11, 487. 
27 B. D. Berezi, P. A. Stuzhin and O. G. Khelevina, Khim. Geterotsikl. Soedin., 1986, 1677; O. G. Khelevina, N. V. Chizhova and P. A. Stuzhin, J. Porphyrins Phthalocyanines, 2000, 4, 555.
28 The effect of protonation on the spectroscopic properties of 4-Zn has been discussed. See J. Schneider, M. Wollenhaupt, A. Winzenburg, T. Bayer, J. Kohler, R. Faust and T. Baumert, Phys. Chem. Chem. Phys., 2011, 13, 8733-8746. 